\title{
6 $\beta$-Hydroxylation of Steroids by Extracts of Aspergillus niger
}

\author{
By I. A. EL-KADY \\ Department of Botany, Faculty of Science, Assiut University, Assiut, Egypt
}

(Received 28 August 1981; revised 19 January 1982)

\begin{abstract}
Growing cultures of Aspergillus niger hydroxylate progesterone at the $6 \beta$ and $11 \alpha$ positions. The properties of the $6 \beta$-hydroxylase activity were studied in extracts of this organism using $11 \alpha$ hydroxyprogesterone as substrate. Maximum $6 \beta$-hydroxylase activity was obtained at $\mathrm{pH} 6.5$. EDTA and thiophenol inhibited hydroxylation, while NADPH, 2-oxoglutarate and pyruvate stimulated it. Cobalt and cadmium ions inhibited the $6 \beta$-hydroxylase activity. The feasibility of introducing a hydroxyl group into the $6 \beta$-position of various steroid compounds was tested: the 3-oxo- $\Delta^{4}$ configuration appeared to exert a directional effect for $6 \beta$-hydroxylation, while an $11 \beta$ hydroxyl group exerted some kind of steric hindrance against $6 \beta$-hydroxylation.
\end{abstract}

\section{INTRODUCTION}

The important discovery by Peterson \& Murray (1952) of the microbiological $11 \alpha$-hydroxylation of progesterone and other steroids led to the use of a variety of micro-organisms for hdyroxylating every position in the steroid nucleus. However, steroid hydroxylation by extracts of micro-organisms has been described in only a few instances. Zuidweg et al. (1962) prepared an extract from Curvuläria lunata capable of catalysing the hydroxylation of Reichstein's compound $\mathrm{S}$ to hydrocortisone. A $9 \alpha$-hydroxylase activity was demonstrated in extracts of Nocardia restrictus by Chang \& Sih (1964). Wilson \& Vestling (1965) obtained an extract from Bacillus megaterium KM able to hydroxylate deoxycorticosterone mainly at the $15 \beta$ position. Zuidweg (1968), using extracts of $C$. lunata, studied the nature of the hydroxylation of Reichstein's compound $S$ at the $11 \beta$ and $14 \alpha$ positions. Sallam et al. (1971), using a cell homogenate of Rhizopus nigricans REF 129, studied the hydroxylation of progesterone at the $11 \alpha, 17 \alpha$ and 21 positions. Nguyen-Dang-Tam et al. (1971) showed that extracts of Aspergillus niger catalysed the hydroxylation of progesterone at the $11 \alpha$ position.

Previously, I have studied the hydroxylation of progesterone at the $11 \alpha$ and $17 \alpha$ positions by extracts of Rhizopus nigricans NRRL 1477 (El-Kady \& Allam, 1973; Allam \& El-Kady, 1975). In this report, I describe an investigation of the $6 \beta$-hydroxylation of progesterone and $11 \alpha$-hydroxyprogesterone by extracts of Aspergillus niger.

\section{METHODS}

Cultures. Aspergillus niger isolate no. 58 (from the Culture Collection of the Mycological Laboratory, Botany Department, Assiut University, Egypt) was cultivated in $250 \mathrm{ml}$ Erlenmeyer flasks which contained $50 \mathrm{ml}$ of the medium described by Capek et al. (1964). The pH was adjusted to 5.6. After sterilization, each flask was inoculated with $2 \mathrm{ml}$ of a spore suspension made from a 1-week old culture. The inoculated flasks were agitated on a reciprocating shaker at $28^{\circ} \mathrm{C}$. After $24 \mathrm{~h}$ growth, the cultures were activated by the addition of $5 \mathrm{mg}$ progesterone per flask and reagitated for another $24 \mathrm{~h}$.

Preparation of extracts. Mycelium was harvested by filtration, washed, thoroughly with $0.5 \%(\mathrm{w} / \mathrm{v}) \mathrm{NaCl}$ solution, followed by distilled water, and blotted dry with absorbent paper. This mycelium ( $15 \mathrm{~g})$ was then ground with cold sand and extracted with $100 \mathrm{ml}$ cold water or $0.1 \mathrm{M}$-potassium phosphate buffer, pH 6.5 . The slurry obtained was centrifuged at $4000 \mathrm{rev} . \mathrm{min}^{-1}$ for $15 \mathrm{~min}$ and the supernatant was used as the enzyme source.

Assay of $6 \beta$-hydroxylating activity in extracts. To $5 \mathrm{ml}$ portions of the extracts in $25 \mathrm{ml}$ Erlenmeyer flasks were added $5 \mathrm{mg} 11 \alpha$-hydroxyprogesterone in $0.1 \mathrm{ml}$ ethanol. The contents were mixed immediately and the flasks were agitated on a reciprocating shaker for $5 \mathrm{~h}$ at $30^{\circ} \mathrm{C}$. At the end of this period the contents of each flask were 
extracted with $10 \mathrm{ml}$ chloroform. Extraction was repeated three times and the combined chloroform extracts were then treated with $0.5 \mathrm{vol}$. of $5 \%(\mathrm{w} / \mathrm{v})$ sodium bicarbonate solution followed by an equal volume of distilled water. The residue was dissolved in a measured volume of chloroform/methanol $(1: 1$, by vol.).

Determination of reaction products. The hydroxylated product in the prepared residue was first identified by conventional thin-layer chromatography with an authentic sample, using cyclohexane/acetone/chloroform $(75: 25: 20$, by vol.) as solvent. The amounts of the product and residual substrate were determined by preparative thin-layer chromatography with the same solvent. The bands containing the compounds were scraped off and eluted with ethanol. The concentration of each was then determined by u.v. spectrophotometric measurement.

\section{RESULTS AND DISCUSSION}

Out of 40 different isolates from five genera (Rhizopus, Mucor, Cunninghamella, Cladosporium and Aspergillus) tested for $6 \beta$-hydroxylation activity, Aspergillus niger isolate no. 58 was the most active and was chosen for further study. Growing cultures of this organism converted $80 \%$ of added progesterone (50 $\mathrm{mg}$ per $50 \mathrm{ml}$ medium) to $11 \alpha$-hydroxyprogesterone $(10 \mathrm{mg}$ ) and $6 \beta, 11 \alpha-$ dihydroxyprogesterone $(30 \mathrm{mg})$ within $48 \mathrm{~h}$.

Using $11 \alpha$-hydroxyprogesterone as a substrate, the stability of the $6 \beta$-hydroxylating activity was tested in extracts stored at 5 and $-10{ }^{\circ} \mathrm{C}$. Extracts kept at $5{ }^{\circ} \mathrm{C}$ lost $90 \%$ of their activity in $24 \mathrm{~h}$ and those kept at $-10{ }^{\circ} \mathrm{C}$ lost $60 \%$ of their activity in the same period. After $48 \mathrm{~h}$ at either temperature all activity was lost. In earlier studies (Chang \& Sih, 1964; El-Kady \& Allam, 1973) microbial steroid-hydroxylating systems were shown to be unstable.

Effect of $p H$. The effect of different $\mathrm{pH}$ values on the $6 \beta$-hydroxylating activity was studied. Portions $(4 \mathrm{ml})$ of the extract in distilled water were adjusted to $\mathrm{pH}$ values ranging from 5.5 to 9 using phosphate or Tris buffers $(500 \mu \mathrm{mol})$. Hydroxylation at the $6 \beta$ position increased with increase in $\mathrm{pH}$, reaching a maximum at $\mathrm{pH} 6.5$. At this $\mathrm{pH}, 42 \%$ of the added $11 \alpha$-hydroxyprogesterone was converted to $6 \beta, 11 \alpha$-dihydroxyprogesterone. At $\mathrm{pH}$ values between 7 and 9 , the $6 \beta$-hydroxylase activity decreased linearly with $\mathrm{pH}$.

Effect of EDTA. EDTA has been used in most studies of the hydroxylation of steroids by extracts of micro-organisms (Zuidweg et al., 1962; Chang \& Sih, 1964; Zuidweg, 1968; Sallam et al., 1971; El-Kady \& Allam, 1973). The effect of different concentrations of this compound on the $6 \beta$-hydroxylating activity was tested. The presence of EDTA at a concentration as low as 5 mM inhibited about $30 \%$ of the $6 \beta$-hydroxylase activity. Higher concentrations of EDTA were more inhibitory (data not presented). This suggests that a metal cation is involved in the hydroxylation.

Effect of some external electron carriers and thiol compounds. A marked stimulation of $6 \beta$ hydroxylase activity was observed in the presence of NADPH (Table 1). 2-Oxoglutarate and pyruvate had a similar effect, but ascorbate, fumarate and succinate were completely inactive. These results are consistent with earlier reports that 2-oxoglutarate stimulates different hydroxylation reactions (Hayaishi, 1969), and that pyruvate can replace 2-oxoglutarate in some enzymic hydroxylation reactions (Hayaishi, 1969).

The effect of some thiol compounds was also studied (Table 2). Glutathione, at a concentration of $5 \mathrm{mM}$, stimulated $6 \beta$-hydroxylase activity, while 2-mercaptoethanol, sodium thioglycolate and cysteine. $\mathrm{HCl}$ had no effect. On the other hand, thiophenol, at the same concentration, caused some inhibition.

Effect of some metal ions. The $6 \beta$-hydroxylase activity was sensitive to $\mathrm{Co}^{2+}$ and $\mathrm{Cd}^{2+}$ which inhibited $80 \%$ and $60 \%$ of the $6 \beta$-hydroxylase activity, respectively (Table 3 ). Previous reports (El-Kady \& Allam, 1973) showed that $\mathrm{Co}^{2+}$ completely inhibited both $11 \alpha$-and $17 \alpha$-hydroxylase activities.

Substrate specificity. The feasibility of introducing a hydroxyl group into the $6 \beta$ position of some steroid compounds was tested. The following compounds were equally active as substrates for the $6 \cdot \beta$-hydroxylase: progesterone, $11 \alpha$-hydroxyprogesterone, $17 \alpha$-hydroxyprogesterone, 21 hydroxyprogesterone, $11 \alpha, 17 \alpha$-dihydroxyprogesterone, epicortisol, testosterone, $11 \alpha$-hydroxytestosterone and androst-4-ene-3,17-dione. In contrast, the following compounds were found to 
Table 1. Effect of some electron carriers on $6 \beta$-hydroxylation

Reaction mixtures (total volume $6 \mathrm{ml}$ ) contained: extract in $0.1 \mathrm{M}$-phosphate buffer, $\mathrm{pH} 6.5,5 \mathrm{ml} ; 11 \alpha$ hydroxyprogesterone, $5 \mathrm{mg}$; test compound, $3 \mathrm{~mm}$. They were incubated at $30^{\circ} \mathrm{C}$ for $5 \mathrm{~h}$ with shaking.

Test compound

None

NADPH

Pyruvate

2-Oxoglutarate

Fumarate

Succinate

Ascorbate

\section{$6 \beta, 11 \alpha$-Dihydroxyprogesterone} formed (mg)

$2 \cdot 10$

$3 \cdot 65$

$3 \cdot 55$

$3 \cdot 60$

$2 \cdot 00$

$2 \cdot 20$

$2 \cdot 00$

Table 2. Effect of some thiol compounds on 6 6 -hydroxylation

Reaction mixtures and assay conditions were as described in the legend to Table 1, except that the test compounds were added at $5 \mathrm{mM}$.

Test compound

None

Glutathione

2-Mercaptoethanol

Sodium thioglycolate

Thiophenol

Cysteine. $\mathrm{HCl}$
$6 \beta, 11 \alpha$-Dihydroxyprogesterone formed (mg)
$2 \cdot 1$
$3 \cdot 1$
$2 \cdot 0$
$2 \cdot 2$
$1 \cdot 4$
$1 \cdot 9$

\section{Table 3. Effect of some metal ions on $6 \beta$-hydroxylation}

Reaction mixtures and assay conditions were as described in the legend to Table 1.

Test compound

None
$\mathrm{ZnSO}_{4}$
$\mathrm{MnSO}_{4}$
$\mathrm{CdSO}_{4}$
$\mathrm{FeSO}_{4}$
$\mathrm{FeCl}_{3}$
$\mathrm{CuCl}_{2}$
$\mathrm{CoCl}_{2}$
$\mathrm{MgCl}_{2}$

$6 \beta, 11 \alpha$-Dihydroxyprogesterone formed (mg)

$$
\begin{aligned}
& 2 \cdot 2 \\
& 2 \cdot 2 \\
& 2 \cdot 1 \\
& 0 \cdot 88 \\
& 2 \cdot 1 \\
& 2 \cdot 0 \\
& 2 \cdot 2 \\
& 0 \cdot 44 \\
& 2 \cdot 0
\end{aligned}
$$

be inactive for the $6 \beta$-hydroxylase: $11 \beta$-hydroxyprogesterone, $11 \alpha$-hydroxy- $5 \alpha$-pregnane-3,20-

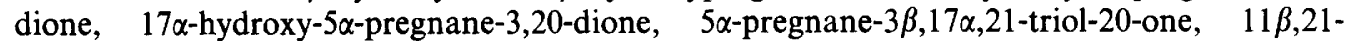
dihydroxyprogesterone, cortisol, cholesterol and ergosterol. It was noted that all the active substrates contained the 3-oxo- $\Delta^{4}$ configuration. Hence, this configuration probably exerts a directional effect for $6 \beta$-hydroxylation. The inactive compounds lack at least one of these two functional groups (3-oxo- $\Delta^{4}$-), except $11 \beta$-hydroxyprogesterone, $11 \beta, 21$-dihydroxyprogesterone and cortisol which contain the 3-oxo- $\Delta^{4}$ configuration but also possess an $11 \beta$-hydroxyl group. Thus, it appears that an $11 \beta$-hydroxyl group exerts some kind of steric hindrance against $6 \beta$ hydroxylation. 


\section{REFERENCES}

Allam, A. M. \& El-Kady, I. A. (1975). The $11 \alpha$ - and $17 \alpha$-progesterone hydroxylases of Rhizopus nigricans NRRL 1477. Acta microbiologica polonica, Series $A$ 7(24), 41-44.

Capek, A., TAdra, M. \& Tuma, J. (1964). Separation of androst-17-hydroxy-epimers. Folia microbiologica 9, 380-382.

Chang, F. N. \& Sih, C. J. (1964). Mechanisms of steroid oxidation by microorganisms. VII. Properties of the $9 \alpha$-hydroxylase. Biochemistry 3, 15511557.

El-Kady, I. A. \& Allam, A. M. (1973). Hydroxylation of progesterone by extracts of Rhizopus nigricans NRRL 1477. Journal of General Microbiology 77, 465-469.

Hayalshi, O. (1969). Enzymic hydroxylation. Annual Review of Biochemistry 38, 21-44.

Nguyen-Dang-Tam, Mayer, M. \& Janot, M. M. (1971). Hydroxylation of progesterone by cell-free extract of Aspergillus niger. Compte rendu hebdomadaire des séances de l'Académie des sciences D272, 2032-2033.
Peterson, D. H. \& Murray, H. C. (1952). Microbiological oxygenation of steroids at carbon 11. Journal of the American Chemical Society 74, 1871-1872.

Sallam, L. A. R., El-Refai, A. H. \& El-Kady, I. A. (1971). The in vitro transformation of progesterone by Rhizopus nigricans REF 129. Zeitschrift für allgemeine Mikrobiologie 11, 325-330.

Wilson, J. A. \& Vestling, C. S. (1965). A cell-free steroid hydroxylating system from Bacillus megaterium, strain KM. Archives of Biochemistry and Biophysics 110, 401-403.

ZUIDWEG, M. H. J. (1968). Hydroxylation of Reichstein's compound $\mathbf{S}$ with cell-free preparation from Curvularia lunata. Biochimica et biophysica acta 152 , 144.

Zuidweg, M. H. J., VAN Der WaARD, W. F. \& De FLINES, J. (1962). Formation of hydrocortisone by hydroxylation of Reichstein's compound $S$ with an enzyme preparation from Curvularia lunata. Biochimica et biophysica acta 58, 131-133. 